\title{
The Impact of Adaptive Complex Assessment on the HOT Skill Development of Students
}

\author{
Jamal Raiyn ${ }^{1, *} \&$ Oleg Tilchin ${ }^{1}$ \\ ${ }^{1}$ Computer Science Department, Al-Qasemi Academic College of Education, Baqa El-Gharbieh, Israel \\ *Correspondence: Computer Science Department, Al-Qasemi Academic College of Education, Baqa El-Gharbieh, \\ Israel. E-mail: raiyn@qsm.ac.il
}

Received: February 3, 2016

Accepted: March 8, 2016 Online Published: March 28, 2016

doi:10.5430/wje.v6n2p12

URL: http://dx.doi.org/10.5430/wje.v6n2p12

\begin{abstract}
In this paper we propose a method for the adaptive complex assessment (ACA) of the higher-order thinking (HOT) skills needed by students for problem solving, and we examine the impact of the method on the development of HOT skills in a problem- based learning (PBL) environment. Complexity in the assessment is provided by initial, formative, and adaptive assessments of HOT skills; assessments of collaborative skills; and summative assessments of HOT skills. Adaptability in the assessment is provided through the dynamics of an instructor's assessments based on developing HOT skills; through a flexible choice of control tests and instructional problems for students and collaborative groups; and through the self-formation of heterogeneous, collaborative HOT skill groups. The assessment fosters the development of HOT and collaborative skills through a combination of personalized and collaborative problem-based learning (PBL). The three-stage assessment process guides the development of HOT skills during subject study through PBL. The focus of the first stage is on developing the HOT skills of students through personalized PBL. The second stage is devoted to developing HOT skills and collaborative skills through collaborative PBL. The third stage is devoted to assessing collaborative skills and constructing summative assessments of students. The proposed calculations for the coefficients of HOT skill development serve as a constructive means of exploring the impact of the ACA method on the HOT skill development of students.
\end{abstract}

Keywords: adaptive complex assessment; higher-order thinking skills

\section{Introduction}

Among the various learning strategies introduced in science education Problem- based learning (PBL) is an important student-centered strategy. It is directed towards the development of the higher-order thinking (HOT) skills that students need for problem solving. For this study, we consider two layers of HOT skills: analytical thinking skills and creative thinking skills. Analytical thinking skills consist of ordering, comparing, contrasting, evaluating, and selecting. Creative thinking skills involve problem finding (identifying the problem), efficiency (producing many ideas), flexibility (producing a broad range of ideas), originality (producing uncommon ideas), and elaboration (developing ideas) (Hmelo-Silver, 2004; Bednarz, 2011; Cottrell, 2011, 2013). Obtaining information about the development of the knowledge, and skills, of a student or group of students is provided by assessment, which serves as an important educational tool (Brown, 2004; Hargreaves, 2007). There are different methods for assessing learning based on home work, examinations, and assignments (Ramsden, 2000; Hamey et. al., 2015). However, these methods do not provide for customization when assessing student performance in a PBL environment. In other words, adaptive assessment is not realized. As a result, students are not induced engage in PBL.

Motivation for students to develop their HOT skills should be provided in PBL environment. It can be attained through specific forms of adaptive assessment. A method for the adaptive complex assessment (ACA) of the HOT skills of students is proposed in this paper, which also examines the impact of the assessment on the development of HOT skills in a problem-based collaborative learning environment. The paper develops an approach to the assessment of HOT skills that can be acquired by students during adaptive PBL (Raiyn \&Tilchin, 2015). 


\section{Related Research}

The goals of teaching and learning with the PBL model are to develop HOT skills, promote the adoption of a problem solving process, and foster collaborative skills in students. The assessment of PBL can serve as a constructive mean of attaining these goals. Various aspects of an assessment process are reviewed here. According to Knight (2000) a systematic approach to the assessment of student learning is needed. Ma and Zhou (2000) suggested an approach to the assessment of learning outcomes aimed at encouraging students to participate in the whole learning process. Moallem (2007) distinguished the following stages of the assessment process: the initial assessment, progress assessment, and product assessment. Tillema (2010) confirmed that the focus of formative assessment is to promote learning. Papanastasiou (2014) defined the adaptive assessment of a student as a type of assessment that is customized to his or her previous performance. Savery (2006) affirmed that one of the objectives of PBL is the adoption of a problem-solving process. Macdonald and Savin-Baden (2004) marked the need for specific assessment methods for PBL. Lovie-Kitchin (2001) claimed that assessment should be coordinated with the PBL process. Ma (2002) developed a decision support system for assessing PBL. Debbie (2009) emphasized the influence of individual assessments on group composition. Swan, Shen and Hiltz (2006) stressed the role of assessment in encouraging of collaborative learning. McLoughlin and Luca (2002) suggested a learner-centered approach to developing collaborative skills through assessment. Analysis survey of the literature shows that there is no method in existence for the adaptive complex assessment of students in a problem-based collaborative learning environment. The proposed method will have a significant impact on the development of HOT skills and the collaborative skills of students, due to the three -staged assessment process for PBL

- the complexity of the assessment

- the self-formed, heterogeneous, collaborative, HOT skills groups of students

- the customization of assessments for the performance of students in a PBL environment.

\section{An Adaptive Complex Assessment Method for HOT Skill Development}

The goal of the ACA method is to promote the guided development of students' HOT skills through a three-stage assessment process for PBL. The first stage involves conducting the initial assessments of HOT skills for individual students, arriving at formative assessments for students' HOT skills, and arranging for self-forming heterogeneous, collaborative HOT skills groups of students on the basis of the formative assessments and the instructor requirements for forming the collaborative groups. The second stage involves conducting adaptive assessments of HOT skills for students and the collaborative groups, and assessing HOT skills of individual students and collaborative groups. The third stage consists of assessing collaborative skills and conducting summative assessments of students. The adaptability of assessment is expressed through the customization of the assessment of student performance in a problem-based collaborative learning environment. The complexity of the assessment follows from conducting initial and formative assessments of the HOT skills of individual students, and the collaborative groups, assessments of collaborative skills, and summative assessments of HOT skills. Assessment is realized through students' replies to control questions and their solving of instructional problems prepared by an instructor.

\subsection{The First Stage of the PBL Assessment Process}

\subsubsection{Conducting Initial Assessments of HOT Skills for Individual Students}

The initial assessments of HOT skills are made during this stage of the PBL assessment. They express the preferences of instructors for developing certain skills in students. Analytical skills are preferred over creative skills at this stage since they provide the basis for the subsequent development of creative skills. The skill termed "evaluating" from among the analytical types of thinking skills shows the greatest need for development, since it is a form of critical thinking. Consequently, the maximal initial assessment is conducted for this skill. Initial assessments of creative skills are schedule order of preference for the development of the problem- solving abilities of students.

Example1: The initial assessments are presented in Table 1. 
Table 1. The Initial Assessments of HOT Skills for Individual Students

\begin{tabular}{lll}
\hline The type of thinking skills & Skills name & The fixed assessments \\
\hline & Evaluating & 24 \\
& Selecting & 18 \\
& Comparing & 13 \\
Analytical (70\%) & Contrasting & 10 \\
& Ordering & 5 \\
\hline & Efficiency & 10 \\
Creative (30\%) & Flexibility & 8 \\
& Originality & 5 \\
& Problem finding & 4 \\
& Elaboration & 3 \\
\hline
\end{tabular}

\subsubsection{Determination of the Formative Assessments of Students' HOT Skills}

Formative assessments make up the first level of the HOT skills development of the study group students. These assessments serve as the basis for setting up the adaptive forming heterogeneous collaborative HOT skills groups of students and for conducting the adaptive assessments of students' HOT skills.

Example 2: The determined formative assessments are represented by Table 2.

Table 2. The Formative Assessments of Student's HOT Skills

\begin{tabular}{|c|c|c|c|c|c|c|c|c|c|}
\hline & $\begin{array}{l}\text { The questions and } \\
\text { instructional problems }\end{array}$ & Skill name & & $\mathrm{S} 1$ & $\mathrm{~S} 2$ & S3 & S4 & S5 & S6 \\
\hline \multirow{8}{*}{$\begin{array}{l}\text { Analytical } \\
\text { skills }\end{array}$} & $\mathrm{q}_{11}$ & Evaluating & $12 \%$ & 8 & 10 & 4 & 7 & 5 & 8 \\
\hline & $\mathrm{q}_{12}$ & Evaluating & $12 \%$ & 9 & 9 & 5 & 6 & 7 & 9 \\
\hline & $\mathrm{q}_{21}$ & Selecting & $9 \%$ & 5 & 7 & 7 & 8 & 5 & 8 \\
\hline & $\mathrm{q}_{22}$ & Selecting & $9 \%$ & 6 & 5 & 5 & 7 & 4 & 7 \\
\hline & $\mathrm{q}_{31}$ & Comparing & $13 \%$ & 9 & 8 & 6 & 11 & 7 & 8 \\
\hline & $\mathrm{q}_{41}$ & Contrasting & $10 \%$ & 7 & 9 & 4 & 7 & 8 & 4 \\
\hline & $\mathrm{q}_{51}$ & Ordering & $5 \%$ & 3 & 2 & 1 & 3 & 4 & 1 \\
\hline & & \multicolumn{2}{|c|}{$\begin{array}{l}\text { The formative assessments of } \\
\text { analytical skills }\end{array}$} & 47 & 50 & 33 & 49 & 40 & 45 \\
\hline \multirow{7}{*}{$\begin{array}{l}\text { Creative } \\
\text { skills }\end{array}$} & $\mathrm{P}_{1}$ & Efficiency & $10 \%$ & 6 & 9 & 5 & 9 & 6 & 7 \\
\hline & $\mathrm{P}_{2}$ & Flexibility & $8 \%$ & 7 & 6 & 4 & 7 & 5 & 5 \\
\hline & $\mathrm{P}_{3}$ & Originality & $5 \%$ & 4 & 4 & 2 & 3 & 3 & 3 \\
\hline & $\mathrm{P}_{4}$ & Problem finding & $4 \%$ & 2 & 2 & 0 & 1 & 0 & 2 \\
\hline & $\mathrm{P}_{5}$ & Elaboration & $3 \%$ & 1 & 2 & 1 & 1 & 2 & 1 \\
\hline & & \multirow{2}{*}{\multicolumn{2}{|c|}{$\begin{array}{l}\text { The formative assessments of } \\
\text { creative skills } \\
\text { The formative assessments of } \\
\text { HOT skills }\end{array}$}} & 20 & 23 & 12 & 21 & 16 & 18 \\
\hline & & & & 67 & 73 & 45 & 70 & 56 & 63 \\
\hline
\end{tabular}

3.1.3 The Self- Formation of Heterogeneous Collaborative, HOT Skills Groups of Students

Each student chooses suitable partner for collaborative PBL by taking into account the formative assessments of HOT skills. The requirements for forming the collaborative groups are determined by the instructor. The requirements are:

- maximum mutual supplementation of the HOT skills of students in each a collaborative group

- taking into account the individual characteristics of students

- keeping to the allowable maximum number of students in a group.

These requirements facilitate the development of skills in cooperating students through interactions that compensate for the lack of personal HOT skills. As a result of mutual choices, the self-formation of a collaborative group is realized. 
Example 3: According to the requirements for forming the collaborative groups and according to the formative assessments of the HOT skills of students (Table 2), two collaborative groups formed themselves. The first collaborative group $\mathrm{g}_{1}$ includes students $\mathrm{s}_{1}, \mathrm{~s}_{3}$, and $\mathrm{s}_{5}$. The second collaborative group $\mathrm{g}_{2}$ includes students $\mathrm{s}_{2}, \mathrm{~s}_{4}$, and $\mathrm{s}_{6}$.

\subsection{The Second Stage of the PBL Assessment Process}

\subsubsection{Conducting Adaptive Assessments of HOT Skills for Students and Collaborative Groups}

Selection adaptive instructional problems for collaborative groups of students is done by taking into account the level of development of their HOT skills: a group with a higher level of skill development should receive more complex instructional problems to solve. Hence, more highly adaptive assessments of creative skills should be given to groups that receive more complex instructional problems.

Example 4: On the basis of the data from Table 2, the formative assessments of the analytical skills of the first and second collaborative groups are 120, and 144, respectively. The formative assessments of the creative skills of the first and second collaborative groups are 48, and 62, respectively. The total formative assessments of the HOT skills of the first and second collaborative groups are 168, and 206, respectively. Consequently, the second collaborative group should receive more complex instructional problems, and more highly adaptive assessments of creative skills for students in this group should be conducted. The adaptive assessments of HOT skills for corresponding collaborative groups are presented in Table3.

Table 3. Adaptive Assessments of HOT Skills for Collaborative Groups

\begin{tabular}{llll}
\hline The type of thinking skill & $\begin{array}{l}\text { Assessments for the first } \\
\text { group }\end{array}$ & $\begin{array}{l}\text { Assessments for the } \\
\text { second group }\end{array}$ \\
\hline Analytical & 30 & 20 \\
Creative & 50 & 60 \\
\hline
\end{tabular}

Adaptive assessments based on formative assessments stimulate and facilitate the acquisition of HOT skills. The adaptive assessments of HOT skills for individual students in the first and second collaborative groups are presented in Table 4.

Table 4. Adaptive Assessments of HOT Skills for Individual Students

\begin{tabular}{|c|c|c|c|}
\hline \multirow[t]{2}{*}{$\begin{array}{l}\text { The type of } \\
\text { thinking skills }\end{array}$} & \multirow[t]{2}{*}{ Skill name } & \multicolumn{2}{|c|}{$\begin{array}{l}\text { The adaptive assessments for individual } \\
\text { students }\end{array}$} \\
\hline & & The first group & The second group \\
\hline & Evaluating & 3 & 2 \\
\hline & Selecting & 7 & 3 \\
\hline & Comparing & 5 & 4 \\
\hline \multirow[t]{2}{*}{ Analytical } & Contrasting & 6 & 5 \\
\hline & Ordering & 9 & 6 \\
\hline & Originality & 8 & 9 \\
\hline \multirow[t]{4}{*}{ Creative } & Efficiency & 12 & 12 \\
\hline & Flexibility & 14 & 7 \\
\hline & Problem finding & 7 & 14 \\
\hline & Elaboration & 9 & 18 \\
\hline
\end{tabular}

A fixed assessment of collaborative skills is introduced to stimulate interactions among students during collaborative problem solving. This assessment is set equal to $20 \%$.

3.2.2 Assessment of the HOT Skills of Individual Students

Assessments received by students as a result of PBCL are presented by Table5. 
Table 5. Assessments of HOT Skills of Individual Students

\begin{tabular}{|c|c|c|c|c|c|c|c|c|}
\hline & \multirow{2}{*}{$\begin{array}{l}\text { The questions and } \\
\text { instructional } \\
\text { problems }\end{array}$} & \multirow[t]{2}{*}{ Skill names } & \multicolumn{3}{|c|}{ The first group } & \multicolumn{3}{|c|}{ The second group } \\
\hline & & & $\mathrm{S} 1$ & S3 & S5 & $\mathrm{S} 2$ & $\mathrm{~S} 4$ & S6 \\
\hline \multirow{6}{*}{$\begin{array}{l}\text { Analytical } \\
\text { skills }\end{array}$} & q1 & Evaluating & 3 & 2 & 2 & 2 & 1 & 2 \\
\hline & $\mathrm{q} 2$ & Selecting & 6 & 5 & 4 & 3 & 3 & 2 \\
\hline & q3 & Comparing & 5 & 3 & 5 & 4 & 3 & 3 \\
\hline & $\mathrm{q} 4$ & Contrasting & 5 & 6 & 5 & 4 & 5 & 4 \\
\hline & q5 & Ordering & 8 & 6 & 8 & 6 & 5 & 4 \\
\hline & & Assessment of analytical skills & 27 & 22 & 24 & 19 & 17 & 15 \\
\hline \multirow{7}{*}{$\begin{array}{l}\text { Creative } \\
\text { skills }\end{array}$} & P1 & Originality & 7 & 5 & 6 & 9 & 9 & 8 \\
\hline & $\mathrm{P} 2$ & Efficiency & 12 & 9 & 10 & 11 & 10 & 10 \\
\hline & P3 & Flexibility & 13 & 12 & 12 & 6 & 7 & 6 \\
\hline & P4 & Problem finding & 7 & 4 & 5 & 13 & 12 & 11 \\
\hline & P5 & Elaboration & 8 & 6 & 9 & 17 & 16 & 15 \\
\hline & & Assessment of creative skills & 47 & 36 & 42 & 56 & 54 & 50 \\
\hline & & Assessment of HOT skills & 74 & 58 & 66 & 75 & 71 & 65 \\
\hline
\end{tabular}

\subsection{The Third Stage of the PBL Assessment Process}

\subsubsection{Assessment of Collaborative Skills}

The collaborative groups are skill heterogeneous within the requirement for the maximal mutual supplementation of skills within a group, which fosters and facilitates skill-sharing among students. The assessment of collaborative skills is based on an analysis of the assessments of the analytical and creative HOT skills of students after collaborative problem solving. The objective of the analysis is to identify the student (or students) who scored highest for HOT skills on this assessment, which would be the result of the acquisition of HOT skills due to collaborative problem solving. This can serve as a measure of the success of collaboration for students, with peers in a group or with members of other collaborative groups. A student with a maximal assessment of HOT skills presumed to possess the best collaborative skills. The assessments of the collaborative skills of students in a group are calculated proportionally to the assessments of HOT skills based on the fixed assessment of collaborative skills. Example5: The fixed assessment of collaborative skills is $20 \%$. This assessment is determined by student $\mathrm{s}_{2}$, since the assessment of the HOT skills of this student is maximal at 75 (Table 5). Hence, the assessment of the collaborative skills achieved by student $\mathrm{s}_{2}$ equals $20 \%$. Student $\mathrm{s}_{3}$ has the worst collaborative skills, since the assessment of HOT skills of this student is minimal at 58 (Table 6). The collaborative skills of student $\mathrm{s}_{3}$ equal $15 \%$. The assessments of the collaborative skills of the remaining students are calculated analogously. The results of the calculations are shown in the third row of Table 7.

\subsubsection{Conducting of Summative Assessments of Students}

The combined summative assessments characterize the outcomes of PBL. These assessments are determined by a summation of the first stage assessments of HOT skills (Table2), the second stage assessments of HOT skills (Table5), and the assessments of collaborative skills (Example5). The results from calculating the combined summative assessments of students are presented in the penultimate row of Table 6. The final summative assessments are presented in the last row of Table 6.

Table 6. The Combined Summative Assessment

\begin{tabular}{lllllll}
\hline & \multicolumn{3}{l}{ The first group } & \multicolumn{3}{l}{ The second group } \\
\cline { 2 - 7 } The assessment type & S1 & S3 & S5 & S2 & S4 & S6 \\
\hline The first stage assessments of HOT skills & 67 & 45 & 56 & 73 & 70 & 63 \\
The second stage assessments of HOT skills & 74 & 58 & 66 & 75 & 71 & 65 \\
Assessments of collaborative skills & 19 & 15 & 17 & 20 & 18 & 16 \\
The combined summative assessments & 160 & 118 & 139 & 168 & 159 & 144 \\
The final summative assessments & 80 & 59 & 70 & 84 & 79 & 72 \\
\hline
\end{tabular}




\subsection{Impact of the ACA Method on HOT Skills Development}

The impact of the ACA method on student's HOT skill development is provided by the sequential application of a three staged assessment process, which consists of (1) assessing the development of students' HOT skills based on the results of the first assessment, (2) assessing the development of students' HOT skills based on the result of the second assessment, and (3) assessing the development of the HOT skills of the collaborative groups. The results of the initial assessment make it possible to assess the development of students' HOT skills by comparing them (Table 1) with the results of formative assessment (Table 2) using the formula:

$$
\delta\left(\mathrm{k}_{\mathrm{i}}\right)=\left(\mathrm{g}^{\mathrm{f}}\left(\mathrm{k}_{\mathrm{i}}\right)-\mathrm{g}\left(\mathrm{k}_{\mathrm{i}}\right)\right) / \mathrm{g}\left(\mathrm{k}_{\mathrm{i}}\right), \quad, \quad-1<\delta\left(\mathrm{k}_{\mathrm{i}}\right) \leq 0
$$

where

$\delta\left(\mathrm{k}_{\mathrm{i}}\right)$ is the coefficient of the development of skill $\mathrm{k}_{\mathrm{i}}$ in a student;

$\mathrm{g}^{\mathrm{f}}\left(\mathrm{k}_{\mathrm{i}}\right)$ is the formative assessment of $\mathrm{k}_{\mathrm{i}}$ skill developed by a student;

$\mathrm{g}\left(\mathrm{k}_{\mathrm{i}}\right)$ is the initial assessment of skill $\mathrm{k}_{\mathrm{i}}$.

Example 6: The formative assessments of the "evaluating" skill for students $\mathrm{s}_{1}, \mathrm{~s}_{3}$, and $\mathrm{s}_{5}$ are 17, 9, and 12, respectively (Table 2). The initial assessment of this skill was equal to24 (Table 1). Therefore, the values of the coefficients for the development of the "evaluating" in these students, according to formula (1) are -029, -063 , and -0.50 , respectively. The values of the coefficients for the development of other skills are determined analogously.

The results of the second stage of assessment make it possible to assess students' developing HOT skills by comparing the results of the individual student assessments (Table5) with the result of the adaptive assessments of individual students (Table4) using the formula (1).

Example 7: The assessment scores for the "evaluating" for students $\mathrm{s}_{1}, \mathrm{~s}_{3}$, and $\mathrm{s}_{5}$ are, 3, 2, and 2, respectively (Table 5). The adaptive assessment of this skill is 3 (Table 4). Therefore, the values of the coefficients for the development of "evaluating" in these students, according to formula (1), are $0,-0.33$, and -0.33 , respectively. The values of the coefficients for development of other skills are determined analogously. A comparison of the values of the coefficients for the development of "evaluating" calculated relative to the first assessment stage (Example 6) and the second assessment stage (Example 7), leads to the conclusion that the ACA method develops this skill in the students of the first collaborative group. Assessing the development of the analytical and creative skills associated with collaborative PBL is realized by comparing corresponding values of the coefficients for the development of these skills from the first and second assessment stages. A coefficient for development $\delta\left(\mathrm{k}_{\mathrm{a}}\right)$ of an aggregate of analytical or creative skills in a student is determined by using the formula:

where

$$
\delta(\mathrm{k})=\left(\mathrm{g}\left(\mathrm{k}_{\mathrm{a}}\right)-\mathrm{g}^{\mathrm{b}}\left(\mathrm{k}_{\mathrm{a}}\right)\right) / \mathrm{g}^{\mathrm{b}}\left(\mathrm{k}_{\mathrm{i}}\right) \quad, \quad-1<\delta\left(\mathrm{k}_{\mathrm{a}}\right) \leq 0
$$

$\mathrm{g}\left(\mathrm{k}_{\mathrm{a}}\right)$ is the assessment of an aggregate of analytical or creative skills possessed by a student and,

$\mathrm{g}^{\mathrm{b}}\left(\mathrm{k}_{\mathrm{a}}\right)$ is the basic (initial or adaptive) assessment of the skill aggregate.

Example 8: The formative assessments of the analytical skills possessed by students $s_{1}, s_{3}$, and $s_{5}$ owing to realizing the first assessment stage are 47,33, and 40, respectively (Table 2). The initial assessment of these skills was equal to70 (Table 1). Therefore, the values of the coefficients for the development of analytical skills in these students, according to formula (2) are $-0.32,-0.53$, and -0.43 respectively. The values of the coefficients of the development of creative skills are calculated analogously.

An analysis of the data from Table 7 leads to the conclusion that the ACA method develops analytical and creative skills in students. 
Table 7. The Coefficient Values for the Development of Aggregates of Skills in Students

\begin{tabular}{|c|c|c|c|c|c|c|c|}
\hline \multirow[b]{2}{*}{ The name of assessment stage } & \multirow[b]{2}{*}{$\begin{array}{l}\text { The name of development } \\
\text { coefficient }\end{array}$} & \multicolumn{3}{|c|}{$\begin{array}{l}\text { The first } \\
\text { Group }\end{array}$} & \multicolumn{3}{|c|}{$\begin{array}{l}\text { The second } \\
\text { group }\end{array}$} \\
\hline & & S1 & S3 & S5 & S2 & S4 & S6 \\
\hline \multirow[t]{2}{*}{ The first assessment stage } & $\begin{array}{l}\text { Coefficient of analytical } \\
\text { skills development }\end{array}$ & -0.32 & -0.53 & -0.43 & -0.29 & -0.30 & -0.36 \\
\hline & $\begin{array}{l}\text { Coefficient of creative } \\
\text { skills development }\end{array}$ & -0.33 & -0.60 & -0.47 & -0.23 & -0.30 & -0.4 \\
\hline \multirow[t]{2}{*}{ The second assessment stage } & $\begin{array}{l}\text { Coefficient of analytical } \\
\text { skills development }\end{array}$ & -0.10 & -0.27 & -0.20 & -0.05 & -0.15 & -0.25 \\
\hline & $\begin{array}{l}\text { Coefficient of creative } \\
\text { skills development }\end{array}$ & -0.06 & -0.28 & -0.16 & -0.07 & -0.10 & -0.17 \\
\hline
\end{tabular}

\section{Conclusion and Future Work}

A method for adaptive complex assessment guiding the development of students' HOT skills through a three-staged assessment process of problem-based collaborative learning is proposed. The adaptability of the assessment is achieved by enabling the customization of the assessments and allowing for a flexible choice of control tests and instructional problems for students and collaborative groups. Complexity in the assessment is achieved by: initial and formative assessments of the HOT skills of individual students, adaptive assessments of HOT skills in individual students and collaborative groups, assessments of collaborative skills, and summative assessments of HOT skills. The method promotes: the adoption of a problem- solving process by students; the self-formation of productive, heterogeneous, collaborative HOT skill groups, and the effective development of HOT and collaborative skills in students. The impact of the adaptive complex assessment on PBL is determined by calculating coefficients for HOT skill development in students. Further research will be directed towards developing mechanism for the adaptive self-formation of collaborative groups, and towards the creation of a computer-supported tool for managing HOT skill development in students.

\section{References}

Bednarz, T. F. (2011). Developing Critical Thinking Skills: Pinpoint Leadership Skill Development Training Series. Majorium Business Press.

Brown, S. (2004). Assessment for Learning. Learning and Teaching in Higher Education, issue 1.

Cottrell, S. (2011). Critical Thinking Skills: Developing Effective Analysis and Argument(2nd edition). Palgrave Macmillan.

Cottrell, S. (2013). The Study Skills Handbook (4th edition.). Palgrave Macmillan,

Debbie, R. (2009). Designing Project-Based Courses with a Focus on Group Formation and Assessment, Journal ACM Transactions on Computing Education (TOCE), 9, 1.

Gray, P. J., \& Diamond, R. M. (1989). Improving higher education: The need for a broad view of assessment. New Directions for Higher Education, 89-107. http://dx.doi.org/0.1002/he.36919896708

Hamey, M. O., Hogan, J.H., Broome, B., Hall, T., \& Ryan. (2015). Investigating the effects of prompts on argumentation style, consensus and perceived efficacy in collaborative learning. International Journal of Computer-Supported Collaborative Learning, 10, 367-394.

Hargreaves, E. (2007). The validity of collaborative assessment for learning. Assessment in Education, 14(2), 1-5.

Hmelo, S., \& Cindy, E. (2004). Problem-Based Learning: What and How Do Students Learn? Educational Psychology Review, 16, 3.

Knight, P.T. (2000). The Value of a Program - wide Approach to Assessment. Assessment and Evaluation in Higher Education, 25(3), 237-251. http://dx.doi.org/10.1080/713611434

Lovie-Kitchin, J. (2001). Reflecting on Assessment, In Schwartz, P. et al. (Eds.), Problem-Based Learning: Case Studies, Experience and Practice. London: Kogan Page.

Ma, J. (2002). Group decision support system for assessment of problem-based learning. Education, IEEE Transition, 
39(3), 388-393. http://dx.doi.org/10.1109/13.538763

Ma, J., \& Zhou, D. (2000). Fuzzy set approach to the assessment of student-centered learning. IEEE Transaction on Education, 43(2), 237-241. http://dx.doi.org/10.1109/13.848079

Macdonald, R., \& Savin-Baden, M. (2004). A Briefing on Assessment in Problem-based Learning, Learning and Teaching Support Network. Retrieved from ftp://www.bioscience.heacademy.ac.uk/Resources/gc/assess13.pdf

McLoughlin, C., \& Luca, J. (2002). A learner-centered approach to developing team skills through web-based learning and assessment. British Journal of Educational Technologies, 33, 5.

Moallem, M. (2007). Assessment of Complex Learning Tasks: A Design Model IADIS, In Proceedings of International Conference on Cognition and Exploratory Learning in Digital Age (CELDA). Retrieved from http://www.coe.missouri.edu/ jonassen/courses/CLE/

Papanastasiou, E. (2014). Adaptive assessment. Encyclopedia of Science Education, 1-2, http://dx.doi.org/10.1007/978-94-007-6165-0

Raiyn, J., \& Tilchin, O. (2015). Evaluation of Adaptive PBL's Impact on HOT Development of Computer Science Students. Journal of Education and Practice, 6(30), 51-58.

Ramsden, P. (2000). Learning to Teach in Higher Education. London: Routledge.

Savery, J. R. (2006). Overview of Problem-based learning: Definitions and Distinctions. The Interdisciplinary Journal of Problem-based learning, 1,1 .

Swan, Karen, Shen, Jia, Hiltz, Starr, \& Roxanne. (2006). Assessment and Collaboration in Online Learning. Journal of Asynchronous Learning Networks. Retrieved from http://www.kent.edu/ehhs/dl/upload/assessment-and-collaborati

Tillema, H. (2010). Formative Assessment in Teacher Education and Teacher Professional Development. International Encyclopedia of Education(3rd editon.), Elsevier. 